\title{
The Influence of Enneagram on Decision Style: Mindfulness as Mediator Variable
}

\author{
Yufei Wang1, Fang $\mathrm{Xu}^{2 *}$, Feng Qin ${ }^{3}$ \\ ${ }^{1}$ Business School, Nanjing Normal University, Nanjing, China \\ ${ }^{2}$ Social Development School, Nanjing Normal University, Nanjing, China \\ ${ }^{3}$ Business School, Jinling Institute of Technology, Nanjing, China \\ Email: bybs2017@163.com, *xfysw@163.com
}

How to cite this paper: Wang, Y.F.., Xu, F. and Qin, F. (2019) The Influence of Enneagram on Decision Style: Mindfulness as Mediator Variable. Open Journal of Social Sciences, 7, 266-281.

https://doi.org/10.4236/jss.2019.74021

Received: March 21, 2019

Accepted: April 20, 2019

Published: April 23, 2019

Copyright () 2019 by author(s) and Scientific Research Publishing Inc. This work is licensed under the Creative Commons Attribution International License (CC BY 4.0).

http://creativecommons.org/licenses/by/4.0/

(c) (i) Open Access

\begin{abstract}
Mindfulness is a state of being focused on the moment, and mindfulness therapy has not only achieved remarkable results in clinical practice, but also been gradually introduced into enterprises. This paper explores the relationship among the three dimensions of Enneagram and decision-making styles, with mindfulness playing a mediating role. We found that except for the thinking-centered dimension of personality, the other two dimensions have a linear correlation with the other three decision-making styles. Mindfulness is positively correlated with moderately alert decision-making style and negatively correlated with others. Mindfulness plays a mediating role between instinct-centered or feeling-centered personalities and four decision-making styles.
\end{abstract}

\section{Keywords}

Enneagram, Mindfulness, Decision-Making Style, Mediation Effect

\section{Introduction}

Decision-making is the most basic pattern of behavior in human life and one of the most important abilities in daily life, which affect all aspects of people's life and work. The research on decision-making style originated in foreign countries and it has received extensive attention in many fields, such as psychology, management, politic and so on since the second half of the $20^{\text {th }}$ century [1]. In a complex and changeable environment, managers must make decisions that affect the fate of individuals and businesses under the uncertainty of inadequate information. Thus it can be seen, decision-making plays an important role in personal life and enterprises. In this case, the individual's personality, ability, *Corresponding author. 
emotion, psychology and other characteristics play an important role in decision-making style [2]. Identifying the characteristics of decision-makers and the impact of psychological effects on decision-making style, and then improving the psychological process of decision-making are the key to rational decision making. In addition, understanding the impact of personality differences on decision-making is also conducive to improving the accuracy of individual and organizational decision-making.

Mindfulness is rooted in eastern meditation, which is a conscious perception and concentration without judging. Mindfulness is applied in medicine and psychology first, and it combines western cranial nerve and psychology [3]. Mindfulness is accepted by more and more mainstream of society. Several famous colleges in America set up study topics about mindfulness and put it in formal curriculum. Now mindfulness is applied in enterprises gradually. Mindfulness-based stress reduction is used to reduce work stress and improve task performance. A mass of practice and researches also prove that mindfulness can reduce stress levels, enhance mental focus, and improve practitioners' happiness and their ability about studying and innovating [4]. People with different characters receive different mindfulness levels and the levels of mindfulness can also influence concentration and veracity when people deal with information [5], and even influence one's decision-making style by influencing endurance with stress when he is dealing with information.

This article will explore how characters can forecast decision-making style and study the relation among three variables by using mindfulness level as the intervening variable.

\section{Literature Review and Hypothesis Development}

\subsection{The Relationship of Enneagram and Decision-Making Style}

Personality refers to the characteristics of temperament, personality, ability and other psychological functions formed by individuals in a certain environment [6]. Although people are continually changing, their main qualities still can be observed in the long term because to some extent these qualities are steady. Therefore, personality can be used as a research object and widely used in psychology, organizational behavior, management and other fields.

Enneagram is an ancient personality typology. Some scholars believe that it derived from Asia and the Middle East (Lapid-Bogda, 2004) [7]. It was introduced into the United States in the 1970s by Claudio Naranjo, a psychiatrist of Chilean, which aroused wide attention in America. Enneagram reveals the pattern of people's choice and existence mode, and divides people into three Categories, Called "the trinity". They present different basic Psychological orientation ang the way that Individuals interact with the external world (Waldberg, 1973) [8], and contain a specific and high-influence change path, indicating the characteristics of evolution and regression. Everyone may contain all nine types, no one is pure personality. all are basic types of mixed personality, but one type 
will be the main factor that determines one's thoughts, feelings and behaviors (Wagner and Walker, 1983) [9].

Instinct-centered including perfectionist, mediator, protector, instinctive center attaches great importance to the action, determination and energy, their own safety, the people of this type do not need to revolve, feelings inward, can directly and lively action, they are interested in things most, pay more attention to itself.

Think-centered including the hedonist, skeptics and observer, they rely on ideas in response to events, attach importance to collect and assess information, tend to analyze the behavior patterns of information, get used to use the brain to analysis, understand, inductive. They are interested in analyzing, but also the easiest to retreat, because they live mainly in imagination.

Feel-centered includes the giver, the doer and the tragic romantic. An emotional person's immediate reaction of things comes from emotions, sensation and feelings. They have strong and sensitive feelings. They are always longing for understanding others and be understood by others.

Decision-making style refers to behavioral patterns of the relatively stable personal characteristics and styles that individuals have when making decisions. The concept of decision style is not established accurately. From the perspective of personal information collection and processing methods, some scholars believe that decision style is determined by the amount of information collected and the number of alternatives considered when making decisions (Driver et al., 1990) [10]. With the development of the field of cognitive psychology, some scholars try to analyze the decision-making style from the point of cognitive style, believing that cognitive style is related to people's attention, processing and evaluation of information, and then will affect the decision-making style (Bieri, 1966) [11].

Janis and Mann (1997) [12] have created the model of decision-making conflict, believing that a person should not be regarded as a rational calculator which can always make right decisions, and that individual characteristics such as mental confusion, conflict, doubt, procrastination, denial of responsibility may affect the process of decision-making. One of the main reasons why people fail in deciding correctly is the conflict of decision-making and the consequent mental pressure. Mann (1997) [12] suggested that the personality variables of stress and information processing ability may partly determine the treating styles that they are most likely to rely on. Hypervigilance and defensive avoidance are non-vigilance decision-making patterns that may be associated with real or imagined time-pressures, emotions, limited attention and other factors. When faced with a decision, people will evaluate that they have the information and resources to deal with the decision. If they think that their resources are insufficient, they will experience emotional anxiety and stress multiplication, etc., and avoid this situation by delaying the decision.

According to social collaboration system school of Barnard's limited rational man hypothesis, people are not "completed rational economic man," but only 
with limited rationally, and decision-making ability limited, the decision-making ability and choose ability is influenced by factors such as personal qualities and environment. Domestic and foreign research shows that the decision will be affected by many individual differences (Liang Zhuyuan, Xu Yan, Jiang Jiang, 2007) [13]. Radford et al. (1986) found in samples of mental patients that there is a positive correlation between the severity of mental disorders and hypervigilance and defensive avoidance [14]. Davis and Grove(1987) [10] and others on the basis of the MBTI personality to explore the relationship of personality and decision-making style, finally found that perceptual type be more effectively than intuition type in a series of decision-making tasks. However, scholars such as Ruble (1990) still have doubts about the decision-making style of MBTI prediction [15]. Robert studied the relationship between personality disorder and decision-making style. Nicholson et al. studied the correlation between the five personality traits and risk-taking in different situational risk decisions. Chen cheng et al. (2018) studied the influence between the big five personality and decision-making style and found that extraversion is positively correlated with intelligent decision-making [16].

Decision makers with different personality types prefer different cognitive models. Different cognitive models differ in information collection and processing affects the decision-making process and ultimately the correctness of the decision. Enneagram can reflect and predict behavioral and cognitive changes. Instinct-centered people tend to gather information unconsciously, foreboding and possibly. Such personality-makers may be too quick to narrow the problem and focus on solutions, instead of gathering a lot of information to fully understand the problem and the situation, so people with this type of personality don't choose a defensive avoidance decision-making style, and they don't make impulsive decisions. Think-centered people tend to process information through logical processes and non-personal objective analysis and are most likely to make rational decisions. Feel-centered people tend to judge information by their personal values and subjective impressions, thus, it is easier to adopt a defensive avoidance decision-making style.

It can be deduced that personality is bound up with decision-making style. Thus the article made the following assumptions.

H1: Think-centered people are related to decision-making style.

H1a: Think-centered people are positively related to the vigilance decision-making style.

H1b: Think-centered people are negatively related to the hypervigilance decision-making style.

H1c: Think-centered people are negatively related to the defensive avoidance decision-making style.

H2: Feel-centered people are related to decision-making style.

H2a: Feel-centered people are positively related to the vigilance decision-making style.

H2b: Feel-centered people are positively related to the hypervigilance deci- 
sion-making style.

$\mathrm{H} 2 \mathrm{c}$ : Feel-centered people are positively related to the defensive avoidance decision-making style.

H3: Instinct-centered people are related to decision-making style.

H3a: Instinct-centered people are positively related to the vigilance decision-making style.

H3b: Instinct-centered people are negatively related to the hypervigilance decision-making style.

H3c: Instinct-centered people are negatively related to the defensive avoidance decision-making style.

\subsection{The Relationship of Enneagram and Mindfulness}

Brown and Ryan (2003) defined mindfulness as "an attribute of consciousness", which means a state that focusing and realizing what is happening at that moment [17]. This is a psychological process involving awareness and attention, and the degree to which consciousness and attention differ in an individual. Langer (1989) pointed out that individuals have different understandings of the environment and state according to a cognitive model and emphasizes the changes of awareness [18]. Also, individual responses to external stimuli are not habitual, but keeping an open-minded and acceptant attitude. As understanding personality differences in mindfulness can improve the individual awareness, so that it helps to make a progress in the individual's mindfulness level and emotional regulation ability.

Research shows individual mindfulness is affected by individual characteristics, and the level of mindfulness is significantly correlated with the big five personality, so we can see that personality characteristics are related to mindfulness level. However, the results of the research on the personality and the level of mindfulness have not been unified yet, and even contradictions. Adam W. Hanley (2016) thinks that these miscellaneous results may be caused by lack of analysis specificity [19]. In conclusion, personality characteristics and mindfulness level have a certain correlation, but how to correlate and what is its internal mechanism have not a unified conclusion.

Instinct-centered people attach more importance on action and are down-to-earth, so they are more likely to have focused attention in action, conscious awareness and a high level of mindfulness. Think-centered people are good at analysis, summary and conclusion, so they also have high attention in action. But compared to the former, they are liable to judge events subjectively, resulting in a low level of mindfulness. Feel-centered people pay more attention to emotions and feelings and are susceptible to the personal subjective factors and emotions. They tend to be affected by subjective factors in observation and not to conduct non-judgmental behavior, resulting in a low level of mindfulness.

Therefore, this article makes the following hypothesis:

H4: Personality characteristics are significantly correlated with the level of 
mindfulness, and mindfulness levels of different personality characteristics are significantly different.

H4a: Instinct-centered people have a positive correlation with mindfulness level.

H4b: Think-centered people have a negative correlation with mindfulness level.

H4c: Feel-centered people have a negative correlation with mindfulness level.

\subsection{The Relationship of Mindfulness and Decision-Making Style}

Mindfulness is a kind of self-control of attention. Keeping attention on the current experience or experience will make individuals maintain a high level of alertness. With the improvement of this alertness, individuals will have a deeper understanding of their current psychological activities. According to the hypothesis of finite rational man, man has only finite rationality and limited decision-making and choice ability. On the one hand, the high attention efficiency brought by mindfulness can expand the boundary of human limited rationality, reduce decision-making mistakes and improve human information processing ability. On the other hand, existing studies have found that mindfulness helps individuals to understand their own state more accurately and has an impact on their perception ability, memory information, emotional regulation and other aspects, so that they can make better behavioral and cognitive choices. Combined with the influence of cognition on decision-making style mentioned above, it can be inferred that the level of mindfulness in this study will have an impact on decision-making style.

In addition, mindfulness can make people not influenced by emotional or psychological processes of attention to the environment of the event, and then evaluate these events through cognitive process, mindfulness training helps to reduce personal pressure, reduce psychological distress, so that people with higher levels of mindfulness can less affected by internal pressure caused by decision, thus can be rational decisions, avoid the non-vigilance decision-making style (Hypervigilance and defensive avoidance).

H5: Decision-making style is significantly correlated with mindfulness level, and people with different levels of mindfulness have obvious differences in decision-making style.

H5a: Levels of mindfulness are positively correlated with vigilance decision-making styles.

H5b: The level of mindfulness is negatively correlated with hypervigilance.

$\mathrm{H} 5 \mathrm{c}$ : There is a negative correlation between mindfulness level and the defensive avoidance decision-making style.

\subsection{The Mediator Role of Mindfulness}

Based on the above assumptions, different personalities have obvious differences in cognitive style, including information processing methods and response pat- 
terns in different situations, which in turn affects their mindfulness level: differences in mindfulness levels lead to bounded rational boundaries and information processing capabilities. The difference is also affected by the pressure of decision-making, so it will affect the decision-making style adopted. Therefore, this paper makes the following assumptions:

H6: The level of mindfulness plays a mediating role in the influence of personality characteristics on decision styles.

\section{Method}

\subsection{Participants}

The data collection is conducted in two ways: online and offline questionnaires. There into online research is mainly distributed through The Questionnaire Survey Platform. Offline questionnaires are distributed mainly in the surrounding areas with dense population. The questionnaires were distributed to students and in-service personnel, and the total is 400 . There into the number of effective questionnaire is 347. Eliminating ineffective questionnaires, the effective rate is $86.75 \%$. Male samples accounted for $47.5 \%$, female samples accounted for $53.5 \%$; ages under 25 accounted for $62.3 \%, 26$ - 35 years old accounted for $17.9 \%, 36$ 45 years old accounted for $13.8 \%, 46$ - 55 years old accounted for $4.9 \%$, accounting for $1.2 \%$ of those over 56 years old; $11.8 \%$ of college education and below, $57.9 \%$ of undergraduates, and $30.3 \%$ of masters and above.

\subsection{Measure}

The core of the Enneagram is to find yourself. Accurate is to discover your inner motivation and understand why I want to pursue these? And why am I troubled? What is the source of these troubles? To put it simply, the theory of Enneagram is to understand the inner motivation of oneself and others.

Mindfulness is "an attribute of consciousness", which means a state that focusing and realizing what is happening at that moment [17]. This is a psychological process involving awareness and attention, and the degree to which consciousness and attention differ in an individual.

The term "decision" generally refers to making choices and decisions from a variety of possibilities. The decision-making style refers to the relatively stable decision-making tendency that individuals form in the long-term decision-making process. Different decision-making styles have a significant impact on decision-making outcomes. The main manifestations are people with different decision-making styles have different preferences for decision-making steps when making decision-making methods, and people with different decision-making styles react differently to the urgency of action. They differ in their attitude towards risk and in dealing with issues.

\section{- Personality characteristics}

In this paper, the Chinese version of the Enneagram Test Scale is used. The scale has good reliability and good validity. Sara Scott (2011) used factor analysis 
of 6401 subjects to examine the structural validity of the Enneagram [16]. The results show that the internal consistency coefficient of each dimension is stable.

\section{- Mindfulness}

In the current mindfulness research measurement, the self-evaluation method is generally used to evaluate the individual's mindfulness level. In this paper, the Mindfulness Attention Awareness Scale (MAAS) will be used to assess individual differences in attentional state over time. The scale uses the Likert 6-point scoring method. In this study, Cronbach alpha for MAAS is 0.871 .

\section{- Decision-making Style}

In this passage, we will employ Melbourne Decision-making Questionaire, which includes 22 items. These sentences describe different decision-making styles and individual behaviors and ideas, which include dimensions: Vigilance ( $\alpha=0.784)$, Hypervigilance ( $\alpha=0.703)$, Buck-passing $(\alpha=0.825)$, Procrastination $(\alpha=0.767)$. Component table adopt Likert 3-point scoring system, divided into never, sometimes and always which correspond 0 - 2 scores. In this study, Cronbach alpha for MDQ is 0.867 .

\section{Result}

\subsection{Correlation Analysis}

We used SPSS20.0 to test the correlation among controlled variable, three types of personality characteristics and decision- making style.

Table 1 shows that Positive correlation between Instinct-centered and mindfulness level $(\beta=0.212, \mathrm{P}<0.01)$; Negative correlation between Feel-centered and mindfulness level $(\beta=-0.166, \mathrm{P}<0.01)$; No correlation between Think-centered and mindfulness level.

There is extremely high correlation between mindfulness level and four decision-making styles. Positive correlation between mindfulness level and Vigilance $(\beta=0.178, \mathrm{P}<0.01)$. Negative correlation among Hypervigilance $(\beta=-0.414, \mathrm{P}<$ $0.01)$, Procrastination $(\beta=-0.462, \mathrm{p}<0.01)$ and Buck-passing $(\beta=-0.487, \mathrm{P}<$ $0.01)$.

Table 1. Results of correlation analysis among variables.

\begin{tabular}{|c|c|c|c|c|c|c|c|c|}
\hline & 1 & 2 & 3 & 4 & 5 & 6 & 7 & 8 \\
\hline Instinctive & 1 & & & & & & & \\
\hline Thinking & $-0.360^{\star *}$ & 1 & & & & & & \\
\hline Feeling & $-0.493^{\star *}$ & $-0.626^{* *}$ & 1 & & & & & \\
\hline Mindfulness & $0.212^{\star *}$ & -0.006 & $-0.166^{\star *}$ & 1 & & & & \\
\hline Vigilance & 0.047 & -0.087 & 0.052 & $0.178^{* *}$ & 1 & & & \\
\hline Hypervigilance & $-0.286^{\star *}$ & 0.020 & $0.204^{\star *}$ & $-0.414^{\star *}$ & $0.249^{* *}$ & 1 & & \\
\hline Procrastination & $-0.227^{\star *}$ & -0.013 & $0.186^{\star *}$ & $-0.462^{\star *}$ & 0.045 & $0.676^{\star *}$ & 1 & \\
\hline Buck-passing & $-0.196^{\star *}$ & -0.006 & $0.148^{\star *}$ & $-0.487^{\star *}$ & -0.079 & $0.628^{\star *}$ & $0.723^{\star *}$ & 1 \\
\hline
\end{tabular}

${ }^{* *}$.signifi ${ }^{* * *}$.significant correlation at 0.01 level (two-sided) ${ }^{*}$.significant correlation at 0.05 level (two-sided). The same as the table below. 
All of personality types and Vigilance had no obvious correlation; Instinct-centered and Hypervigilance, Procrastination, Buck-passing had significant negative correlation $(\beta=-0.286,-0.227,-0.196, \mathrm{p}<0.01)$; Feel-centered and Hypervigilance, Procrastination, Buck-passing had significant positive correlation $(\beta=0.204,0.186,0.148, \mathrm{p}<0.01)$; Think-centered and non-vigilance decision-making styles had no obvious correlation.

\subsection{Regression Analysis}

This article used SPS20.0 in gender, age, level of education, marriage status, whether to participate in the work as control variables, with nine personality three dimensions as independent variables, mindfulness level as intermediary variable, decision-making style as outcome variables to explore the relationship between the three variables, by multivariate hierarchical regression method.

The three-step regression method of Wen Zhonglin (2014) was adopted to test the mediating effect of mindfulness in the article [20]. Which means exploring the significance of $c, a, b$ and $c^{\prime}$ respectively, and verifying the mediating effect hypothesis of mindfulness further in this article by using SPSS 20.0.

As shown in Table 2, Model $1-3$ is a regression model with mindfulness as the dependent variable, and the independent variable is gradually added into the instinct-centered, think-centered and feel-centered to analyze the significance of the mediating variable and the coefficient of the independent variable in the mediating effect. It shows that instinct-centered positively influences the level of mindfulness $(\mathrm{a}=0.831, \mathrm{p}<0.01)$. Think-centered is not related to the level of mindfulness; The feel-centered negatively affects the level of mindfulness $(\mathrm{a}=$ $-0.52, \mathrm{p}<0.05)$.

In summary, regression coefficient a of both the instinctive/feeling center and the mediating variable is significant, and $\mathrm{H} 4 \mathrm{a}$ and $\mathrm{H} 4 \mathrm{c}$ were assumed to be true.

Model 4 - 7 is regression model, in which vigilance is the dependent variable, and we add Instinctive/Thinking/Feeling Center gradually to independent variables. According to the inspection methods of mediating effect, brought forward by Wen Zhonglin, the mediating variable $\mathrm{c}$ is not significant, so the mediating effect of mindfulness doesn't account for the relationship between Enneagram and vigilance.

As shown in Table 3, model $1-3$ is the regression model that uses hypervigilance as the dependent variable and adds Instinctive/Thinking/Feeling Center

Table 2. Results of Enneagram, mindfulness and vigilance regression analysis.

\begin{tabular}{|c|c|c|c|c|c|c|c|c|c|c|}
\hline \multirow{2}{*}{ Dependent Variable } & M 1 & M 2 & M 3 & M 4 & M 5 & M6 & M 7 & M 8 & M 9 & M 10 \\
\hline & \multicolumn{3}{|c|}{ Mindfulness } & \multicolumn{7}{|c|}{ Vigilance } \\
\hline Instinctive & $0.831^{*}$ & & & 0.056 & & & & 0.019 & & \\
\hline Thinking & & -0.006 & & & -0.099 & & & & -0.098 & \\
\hline Feeling & & & $-0.520^{*}$ & & & 0.061 & & & & 0.086 \\
\hline Mindfulness & & & & & & & $0.046^{* *}$ & $0.045^{\star *}$ & $0.046^{* *}$ & $0.048^{* * *}$ \\
\hline
\end{tabular}


gradually to independent variables. Based on pattern $1-3$, the independent variable mindfulness is added to pattern 5 - 6. In pattern $1-4$, instinct-centered has a negative effect on hypervigilance $(c=-0.267, \mathrm{P}<0.001)$; think-centered has no relevance to hypervigilance; feel-centered has a positive effect on hypervigilance $(c=0.155, \mathrm{P}<0.01)$. In pattern 6 , mindfulness has a negative effect on hypervigilance $(\mathrm{b}=-0.07, \mathrm{P}<0.001)$; instinct-centered has a negative effect on hypervigilance $\left(c^{\prime}=-0.209, \mathrm{P}<0.01\right)$. In pattern 7 , mindfulness has a negative effect on hypervigilance $(\mathrm{b}=-0.075, \mathrm{P}<0.05)$; the coefficient of feel-centered and hypervigilance is not noticeable. In pattern 8 , mindfulness has a negative effect on hypervigilance $(b=-0.072, P<0.001)$; feel-centered has a positive effect on hypervigilance $\left(c^{\prime}=0.118, \mathrm{P}<0.05\right)$.

As is discussed above, the regression coefficients of instinctive/feeling center and result variables excessive alertness is noted. Suppose H2b, H3b is valid; mindfulness negatively influences the excessive alertness. H5b established, and mindfulness partly works as a medium in the influence of over-alert.

As shown in Table 4, in model 1 - 3, instinct-centered affects tarriance negatively ( $\mathrm{c}=-0.267, \mathrm{p}<0.001)$; think-centered does not relate to procrastination; feeling-centered has a positive influence on procrastination $(c=0.18, p<0.01)$. In model 4 , mindfulness positively affect procrastination $(b=-0.097, p<0.001)$ while instinct-centered has the contrary effect $\left(c^{\prime}=-0.186, p<0.01\right)$. In model 5 , mindfulness affects procrastination negatively and the coefficient between feel-centered $(b=-0.102, p<0.05)$ and procrastination is not significant. In model 6, mindfulness has a negative effect on procrastination $(b=-0.098, p<$ $0.001)$ and feel-centered acts in a totally different way $\left(c^{\prime}=0.129, \mathrm{p}<0.05\right)$.

As shown in Table 5, in model 1 - 3, the instinct-centered had a negative influence on the buck-passing ( $c=-0.252, \mathrm{P}<0.01$ ); the think-centered had no

Table 3. Results of Enneagram, mindfulness and hypervigilance regression analysis.

\begin{tabular}{|c|c|c|c|c|c|c|}
\hline \multirow{2}{*}{ Dependent Variable } & M 1 & M 2 & M 3 & M 4 & M 5 & M 6 \\
\hline & \multicolumn{6}{|c|}{ Hypervigilance } \\
\hline Instinctive & $-0.267^{* * *}$ & & & $-0.209^{* *}$ & & \\
\hline Thinking & & 0.006 & & & 0.005 & \\
\hline Feeling & & & $0.155^{\star *}$ & & & $0.118^{\star}$ \\
\hline Mindfulness & & & & $-0.07^{\star * *}$ & $-0.075^{*}$ & $-0.072^{\star * *}$ \\
\hline
\end{tabular}

Table 4. Results of Enneagram, mindfulness and procrastination regression analysis.

\begin{tabular}{ccccccc}
\hline \multirow{2}{*}{ Dependent Variable } & M 1 & M 2 & M 3 & M 4 & M 5 & M 6 \\
\cline { 2 - 7 } & & \multicolumn{5}{c}{ Procrastination } \\
\hline Instinctive & $-0.267^{* * *}$ & & & $-0.186^{* *}$ \\
Thinking & & -0.023 & & & -0.023 & \\
Feeling & & & $0.180^{* *}$ & & & $0.129^{*}$ \\
Mindfulness & & & & $-0.097^{* * *}$ & $-0.102^{*}$ & $-0.098^{* * *}$ \\
\hline
\end{tabular}


Table 5. Results of Enneagram, mindfulness and buck-passing regression analysis.

\begin{tabular}{ccccccc}
\hline \multirow{2}{*}{ Dependent Variable } & M 1 & M2 & M 3 & M 4 & M 5 & M 6 \\
\cline { 2 - 6 } & \multicolumn{5}{c}{ Buck-passing } \\
\hline Instinctive & $-0.252^{* *}$ & \multicolumn{5}{c}{-0.146 } \\
Thinking & & -0.026 & & -0.027 & \\
Feeling & & & $0.166^{*}$ & & & 0.098 \\
Mindfulness & & & & $-0.128^{* * *}$ & $-0.132^{* *}$ & $-0.130^{* * *}$ \\
\hline
\end{tabular}

relationship with the buck-passing; and the feel-centered had a positive influence on the buck-passing $(c=0.166, \mathrm{P}<0.05)$.

In model 4 , the mindfulness negative influence buck-passing $(\mathrm{b}=-0.128, \mathrm{P}<$ 0.001); the coefficient $C^{\prime}$ of instinct-centered was not significant. In model 5, mindfulness negatively affected the buck-passing $(\mathrm{b}=-0.132, \mathrm{P}<0.01)$; the think-centered and the coefficient of buck-passing were not significant. In model 6 , mindfulness negatively affects buck-passing $(\mathrm{b}=-0.13, \mathrm{P}<0.001)$; the coefficient C' of feel-centered is not significant.

To sum up, the regression coefficients of instinctive/feeling center and procrastination/buck-passing were significant, and $\mathrm{H} 2 \mathrm{c} \& \mathrm{H} 3 \mathrm{c}$ was assumed to be true. Mindfulness was negatively correlated with procrastination/buck-passing, and $\mathrm{H} 5 \mathrm{c}$ was assumed to be true. Mindfulness plays a partial mediating role in the effect of the instinctive/feeling center on procrastination and plays a complete mediating role in the influence of instinct/feeling center on buck-passing.

\subsection{Bootstrap Analysis}

Further verification for the conclusion of mediating effect given above, we take mediating effect analysis program proposed by Zhao et al. in 2010, refer to the method of Bootstrap proposed by Preacher in 2004 and Hayes in 2013 [21], utilize SPSS plug-in components process 2.16 to analyze mediating effect. It takes three dimensions of enneagram as independent variable ( $\mathrm{X}=$ instinct-centered, think-centered, feel-centered), the style of decision making as dependent variable ( $\mathrm{Y}$ = vigilance, hypervigilance, procrastination, buck-passing), the mindfulness as intermediate variable ( $\mathrm{M}=$ mindfulness). Extraction times is 5000 and confidence internal is $95 \%$. After putting variable into the program, the results are as follow.

Table 6 represents the intermediary route of Integrity in independent and dependent variables. As can be seen from the table above, test results of the intermediary between instinct-centered/feel-centered and four decision-making styles all exclude 0 , which suggests that integrity produces significant intermediary effect during the process.

Table 7 resents the direct effect of the independent variable three dimensions on the dependent variable decision-making style after intermediary variable is under control. As can be seen from the table above, 0 is included between LLCI and ULCI of instinctive/feeling center on vigilance/buck-passing, it suggests that 
Table 6. Indirect effect of Enneagram on decision-making style.

\begin{tabular}{cccccc}
\hline Decision-making Style & Dimensions & Effect & Boot SE & LLCI & ULCI \\
\hline \multirow{3}{*}{ Vigilance } & Instinctive & 0.0376 & 0.0193 & 0.0069 & 0.0853 \\
& Thinking & -0.0003 & 0.0129 & -0.0272 & 0.0259 \\
& Feeling & -0.0248 & 0.0135 & -0.0581 & -0.0031 \\
& Instinctive & -0.0578 & 0.0273 & -0.1199 & -0.0104 \\
Hypervigilance & Thinking & 0.0005 & 0.0211 & -0.0393 & 0.0435 \\
& Feeling & 0.0374 & 0.0201 & 0.0020 & 0.0823 \\
& Instinctive & -0.0806 & 0.0362 & -0.1576 & -0.0140 \\
Procrastination & Thinking & 0.0006 & 0.0278 & -0.0552 & 0.0542 \\
& Feeling & 0.0512 & 0.0267 & 0.0005 & 0.1063 \\
& Instinctive & -0.1068 & 0.0464 & -0.2045 & -0.0226 \\
& Thinking & 0.0008 & 0.0366 & -0.0679 & 0.0757 \\
& Feeling & 0.0675 & 0.0377 & 0.0058 & 0.1382 \\
\hline
\end{tabular}

Table 7. Direct effect of Enneagram on decision style.

\begin{tabular}{cccccc}
\hline Decision-making Style & Dimensions & Effect & SE & LLCI & ULCI \\
\hline \multirow{2}{*}{ Vigilance } & Instinctive & 0.0188 & 0.0758 & -0.1304 & 0.1680 \\
& Thinking & -0.0983 & 0.0635 & -0.2232 & 0.0266 \\
& Feeling & 0.0857 & 0.0612 & -0.0348 & 0.2062 \\
& Instinctive & -0.2092 & 0.0626 & -0.3323 & -0.0860 \\
Hypervigilance & Thinking & 0.0053 & 0.0534 & -0.0998 & 0.1104 \\
& Feeling & 0.1177 & 0.0511 & 0.0171 & 0.2182 \\
\multirow{3}{*}{ Procrastination } & Instinctive & -0.1860 & 0.0699 & -0.3225 & -0.0484 \\
& Thinking & -0.0232 & 0.0593 & -0.1399 & 0.0935 \\
& Feeling & 0.1292 & 0.0568 & 0.0175 & 0.2409 \\
& Instinctive & -0.1455 & 0.0806 & -0.3041 & 0.0131 \\
& Thinking & -0.0269 & 0.0681 & -0.1607 & 0.1070 \\
& Feeling & 0.0984 & 0.0654 & -0.0302 & 0.2270 \\
\hline
\end{tabular}

mindfulness is not the only intermediary variable; and 0 is excluded between LLCI and ULCI of instinctive/feeling center on moderate alertness/shirking responsibilities, it suggests that integrity is the only intermediary variable.

\section{Discussion}

Based on the theories of Enneagram, mindfulness and decision-making styles, we made several hypotheses and envisaged a model. By doing statistical analysis of more than 300 questionnaires collected online and offline, we have tested the research hypotheses above and reached the following findings:

1) The influence of Enneagram on decision-making styles 
By doing empirical studies, we have verified the influence of the feel-centered and instinct-centered dimensions of enneagram on non-vigilance decision-making style: decision-making styles can be predicted based on personality traits. People with different personalities tend to differ from each other significantly in decision-making styles. Feel-centered people tend to make judgment out of their emotions and subjective senses, so that they are susceptible to personal preferences when collecting and processing information; and when making decisions, they can be easily affected by the pressure stem from decision-making conflicts. As a result, they incline to adopt a non-vigilance decision-making style when making decisions. So $\mathrm{H} 2 \mathrm{~b}$ and $\mathrm{H} 2 \mathrm{c}$ are true.

Instinct-centered people rely more on their natural response and focus on actions and solutions when they act, so that they will not withdraw from decision-making when facing decision-making conflicts. People with this type of personality pursue perfection more compared to those with the other two types. They are like perfectionists who try to minimize the risk of making mistakes and avoid impulsive decisions. When making decisions, instinct-centered people will try to avoid non-vigilance decisions. So $\mathrm{H} 3 \mathrm{~b}$ and $\mathrm{H} 3 \mathrm{c}$ are proved.

We found no significant correlation between personalities and moderately alert decision-making style in the empirical studies above. The Investigator is good at and prefer analyzing and logical thinking; they may otherwise trap themselves in one sole mode of thinking. The Loyalist means being responsible, trustworthy, dedicated and having strong capability; however, people with this kind of personality may often be too cautious to make quick react. The Enthusiast likes exploring and analyzing new things. On the one hand, they are energetic, straightforward and confident. They attach great importance to the outcome. On the other hand, they like to escape and are in lack of patience and persistence.

Through the analysis above, we can see that think-centered people suffer inner contradictions in information processing and decision-making. For example, The Investigator are good at analyzing and logical thinking. They prefer rational decision making. They are easy to be trapped in a dilemma, resulting in procrastination or hypervigilance. Therefore, no significant correlation was found between thinking-centered personality and decision-making styles.

2) The influence of Enneagram on mindfulness level

By doing empirical studies, we have verified the influence of the three dimensions of Enneagram on mindfulness level: instinct-centered personality has a positive effect on mindfulness level, feel-centered personality has a negative impact on mindfulness level, think-centered personality has no correlation with mindfulness level. Instinct-centered people emphasize action and pursue perfection, so they will pay more attention when working and thus have a higher level of mindfulness. So H4a is true. Feel-centered people tend to think more about their emotions when taking actions. They are susceptible to emotions and pressures, which will lead to inattention and are easily dominated by emotions, which will cause non-vigilance. Their level of mindfulness is relatively low, so 
$\mathrm{H} 4 \mathrm{c}$ is proved. No correlation between think-centered personality and mindfulness level was found. We assume that: on the one hand, think-centered people are good at analyzing and summarizing in decision-making, and thus maintain a high level of attention. At the same time, they will probably overestimate information. The two factors are counterbalanced, resulting in no significant correlation. So $\mathrm{H} 4 \mathrm{~b}$ is falsified.

3) The influence of mindfulness level on decision-making styles

Through empirical studies, we have verified the influence of mindfulness on decision-making styles: Mindfulness level has a positive influence on vigilance and a negative effect on non-vigilance decision-making style. In other words, the higher the mindfulness level is, the easier it is for one to make the right decision. From the perspective of information collecting and processing, people with high mindfulness level have higher attention efficiency, which improves their self-assessment ability and information processing ability. Thus, they can face decision-making conflicts more rationally. From the perspective of psychological pressure in the face of decision-making conflicts, people with high mindfulness level are adept in regulating their own emotions and pressures and avoid being affected by pressure when making decisions. On the contrary, people with low mindfulness level tend to believe their selective perception, which leads to biased cognition. Misled by it, they will end up with non-vigilance decision-making. Therefore, H5 has been proved correct.

4) The mediating role of mindfulness level

From the regression results and Bootstrap results above, we can see that mindfulness plays a mediating role in the influence of feeling or instinctive center personality on decision-making styles. In the regression results, the general effect of feeling or instinctive center personality on vigilance decision-making style is not significant; but in Bootstrap results, mindfulness plays a mediating role in the influence of feeling or instinctive center personality on vigilance decision-making style, with other mediating variables involved. So, we think there exist other mediating variables balancing out the effect of mindfulness. Thus, the main effect is not significant. In conclusion, people with different personality traits have different levels of mindfulness, which leads to significant differences in cognitive ability and psychological endurance. This difference also results in different decision-making styles. So H6 has been confirmed.

\section{Conclusions}

This paper studies the relationship among personalities, mindfulness and decision-making styles, enriches the academic achievements about mindfulness theory in the field of organizational behavior and provides a reference for predicting mindfulness level and decision-making styles from personality. According to this paper, decision-making ability can be improved and rational decisions can be made by raising mindfulness level. Theoretical basis is provided for rational decision making. Based on the conclusions above, we propose the fol- 
lowing suggestions:

1) Improve mindfulness level and decision-making ability

Mindfulness has been proved to have a significant effect on improving individual's psychological cognition and relieving psychological pressure. People with high mindfulness level can maintain a high level of concentration and view things from various perspectives, which will help to increase their work efficiency, reduce the negative impact of pressure and improve sense of identity and job satisfaction, and thus lead to more rational decisions. Currently, mindfulness training courses have already been adopted by companies including Google and Apple to relieve stress and improve efficiency. Therefore, both individuals and organizations should value the role of mindfulness and take measures to improve the mindfulness level of employees.

2) Make full use of the predictive function of personality traits

This paper confirms the influence of personality on mindfulness level and decision-making styles, which reveals the predictive role of personality. Personality testing has been used by many enterprises in job matching. We believe that the predictive function of personality is not only useful in job matching but can also predict the mindfulness level and decision-making style of employees, which is conducive to personalized training and management of employees. For individuals, it can help them understand their own personality more accurately and conduct self-management accordingly.

\section{Conflicts of Interest}

The authors declare no conflicts of interest regarding the publication of this paper.

\section{References}

[1] Mann, L., Radford, M., Burnett, P., Ford, S., Bond, M., Leung, K., Vaughan, G., Nakamura, H. and Yang, K.S. (1998) Cross-Cultural Differences in Self-Reported Decision-Making Style and Confidence. International Journal of Psychology, 33, 325-335. https://doi.org/10.1080/002075998400213

[2] Huang, R. (2016) The Relationship between Individual Power Sense and Decision-Making Style. Master's Thesis, Hunan Normal University, Hunan.

[3] Kabat-Zinn, J. (2005) Wherever You Go, There You Are: Mindfulness Meditation in Everyday Life. Hyperion, New York.

[4] Hüilsheger, U.R., Alberts, H.J.E.M., Feinholdt, A., et al. (2013) Benefits of Mindfulness at Work: The Role of Mindfulness in Emotion Regulation, Emotional Exhaustion, and Job Satisfaction. Journal of Applied Psychology, 98, 310-325.

https://doi.org/10.1037/a0031313

[5] Giluk, T.L. (2009) Mindfulness, Big Five Personality, and Affect: A Meta-Analysis. Personality and Individual Differences, 47, 806-811. https://doi.org/10.1016/j.paid.2009.06.026

[6] Albert, J.L. (2001) First-Generation Female Higher Education Student Affairs Personnel: The Significance of Personality and Spirituality. Unpublished Doctorial Dissertation, Capella University, Minneapolis, MN. 
[7] Lapid-Bogda, G. (2004) Bringing out the Best in Yourself at Work: How to Use the Enneagram System for Success. McGraw-Hill, New York.

[8] Waldberg, M. (1973) Gurdjieff: An Approach to His Ideas. Penguin Books, New York.

[9] Wagner, J.P. and Walker, R.E. (1983) Reliability and Validity Study of a Sufi Personality Typology: The Enneagram. Journal of Clinical Psychology, 39, 712-717. https://doi.org/10.1002/1097-4679(198309)39:5<712::AID-JCLP2270390511>3.0.CO $\underline{2-3}$

[10] Davis, D.L., Grove, S.J. and Knowles, P.A. (1990) An Experimental Application of Personality Type as an Analogue for Decision Making Style. Psychological Reports, 66, 167-175. https://doi.org/10.2466/pr0.1990.66.1.167

[11] Bieri, J. (1966) Cognitive Complexity and Personality Development. In: Harvey, O.J., Ed., Experience, Structure and Adaptability, Springer, Berlin, Heidelberg, 13-37. https://doi.org/10.1007/978-3-662-40230-6_3

[12] Mann, L., Burnett, P., Radford, M. and Ford, S. (1997) The Melbourne Decision Making Questionnaire: An Instrument for Measuring Patterns for Coping with Decisional Conflict. Journal of Behavioral Decision Making, 10, 1-19. https://doi.org/10.1002/(SICI)1099-0771(199703)10:1<1::AID-BDM242>3.0.CO;2-X

[13] Liang, Z.-Y., Xu, Y. and Jiang, J. (2007) A Review of the Research Status of Individual Differences in Decision-Making. Advances in Psychological Science, No. 4, 689-694.

[14] Radford, M., Mann, L. and Kalucy, R.S. (1986) Psychiatric Disturbance and Decision-Making. Australian and New Zealand Journal of Psychiatry, 20, 210-217. https://doi.org/10.3109/00048678609161333

[15] Ruble, T.L. and Cosier, R.A. (1990) Effects of Cognitive Styles and Decision Setting on Performance. Organization Behavior and Human Decision Processes, 46, 283-295. https://doi.org/10.1016/0749-5978(90)90033-6

[16] Chen, C., Liu, L.-H., Xue, Y.-G. and Xu, H.-Y. (2013) Decision-Making Style of College Students and Its Relations with Extroversion and Neuroticism. Journal of Weifang Engineering Vocational College, 26, 61-64.

[17] Brown, K.W. and Ryan, R.M. (2003) The Benefits of Being Present: Mindfulness and Its Role in Psychological Well-Being. Journal of Personality and Social Psychology, 84, 822-848. https://doi.org/10.1037/0022-3514.84.4.822

[18] Langer, E.J. (1989) Minding Matters: The Consequences of Mindlessness-Mindfulness. Advances in Experimental Social Psychology, 22, 137-173. https://doi.org/10.1016/S0065-2601(08)60307-X

[19] Hanley, A.W. (2016) The Mindful Personality: Associations between Dispositional Mindfulness and The Five Factor Model of Personality. Personality and Individual Differences, 91, 154-158. https://doi.org/10.1016/j.paid.2015.11.054

[20] Wen, Z.-L. and Ye, B.-J. (2014) Mediation Effect Analysis: Method and Model Development. Advances in Psychological Science, 22, 731-745. https://doi.org/10.3724/SP.J.1042.2014.00731

[21] Chen, R., Zheng, Y.-H. and Liu, W.-J. (2013) Mediation Effect Analysis: Principle, Procedure, Bootstrap Method and Its Application. Journal of Marketing Science, 9, 120-135. 